\title{
P90 Indexing Left Ventricular Mass to Body Size: Which Method is the Most Appropriate in Early Adulthood?
}

\author{
Hannah Taylor ${ }^{1, *}$, Chloe Park ${ }^{1}$, Abigail Fraser ${ }^{2}$, Laura Howe $^{2}$, Dianna Ferreira ${ }^{2}$, Nic Timpson ${ }^{2}$, Debbie Lawlor ${ }^{2}$, \\ George Davey-Smith ${ }^{2}$, Nishi Chaturvedi ${ }^{1}$, Alun Hughes ${ }^{1}$
}

${ }^{1}$ Cardiometabolic Phenotyping Group, University College London, London, UK

${ }^{2} M R C$ Integrative Epidemiology Unit, University of Bristol, Bristol, UK

\section{ABSTRACT}

Introduction: Left ventricular mass (LVM) predicts cardiovascular risk. In early life, LVM is conventionally indexed to height 2.7 [1], although this may not account for sex differences in growth. We investigated allometric scaling of LVM to height, lean mass (LM) and body surface area (BSA) in a UK birth cohort.

Methods: 861 individuals underwent echocardiography to assess LVM at age 17.7 (SD 0.3) years and 24.0 (SD 0.6) years. LM was quantified using dual-energy X-ray absorptiometry. Group and sex-specific allometric relationships were determined by linear regression, following $\log$ transformation of $\mathrm{x}$ and $\mathrm{y}$ variables $\left(\log (y)=a+b^{*} \log (x)\right)(b=$ scaling exponent).

Results: LVM showed a linear relationship with LM and $\log ($ height), although the intercepts differed by sex. At age 17, the exponent relating LVM to height in males and females combined was 2.67 (95\% CI: 2.41, 2.91), very close to the suggestion of height 2.7. Sex-specific estimates for height were lower and close to the estimate of 1.7 [2], at $1.77(1.17,2.37)$ and $1.83(1.35,2.31)$, for males and females, respectively. The female exponent at age 24 remained close to 1.7 , while the male exponent increased to $2.14(1.54,2.73)$. Exponents for LM and BSA remained similar between ages 17 and 24 (see Table 1 for detail)

Conclusion: A universal approach for allometric indexing of LVM may be inappropriate in early adulthood, and indexation may need to be both age- and gender-specific. It remains unclear which indexing method is superior at these ages, although height may be unsuitable. These observations may have important implications for identifying young individuals with cardiac hypertrophy.

Table 1

\begin{tabular}{|c|c|c|c|c|c|c|c|c|c|c|}
\hline & & \multicolumn{3}{|c|}{ Height } & \multicolumn{3}{|c|}{ Lean } & \multicolumn{3}{|c|}{ BSA } \\
\hline & & $n$ & $\begin{array}{l}\text { Coefficient } \\
(+95 \% \mathrm{CI})\end{array}$ & $p$ & $n$ & $\begin{array}{l}\text { Coefficient } \\
(+95 \% \mathrm{CI})\end{array}$ & $p$ & $n$ & $\begin{array}{l}\text { Coefficient } \\
(+95 \% \text { CI })\end{array}$ & $p$ \\
\hline \multirow[t]{3}{*}{ Age 17} & Group & 861 & $2.67(2.41,2.91)$ & $<0.001$ & 861 & $0.85(0.80,0.91)$ & $<0.001$ & 861 & $1.76(1.64,1.88)$ & $<0.001$ \\
\hline & Male & 333 & $1.77(1.17,2.37)$ & $<0.001$ & 333 & $1.18(1.00,1.36)$ & $<0.001$ & 333 & $1.69(1.45,1.93)$ & $<0.001$ \\
\hline & Female & 528 & $1.83(1.35,2.31)$ & $<0.001$ & 528 & $1.10(0.96,1.24)$ & $<0.001$ & 528 & $1.36(1.20,1.53)$ & $<0.001$ \\
\hline \multirow[t]{3}{*}{ Age 24} & Group & 861 & $2.97(2.70,3.23)$ & $<0.001$ & 861 & $1.07(1.01,1.13)$ & $<0.001$ & 861 & $1.78(1.66,1.90)$ & $<0.001$ \\
\hline & Male & 333 & $2.14(1.54,2.73)$ & $<0.001$ & 333 & $1.20(1.05,1.35)$ & $<0.001$ & 333 & $1.60(1.36,1.84)$ & $<0.001$ \\
\hline & Female & 528 & $1.65(1.11,2.19)$ & $<0.001$ & 528 & $1.10(0.98,1.23)$ & $<0.001$ & 528 & $1.32(1.15,1.50)$ & $<0.001$ \\
\hline
\end{tabular}

\section{REFERENCES}

[1] de Simone G, Daniels SR, Devereux RB, Meyer RA, Roman MJ, de Divitiis O, et al. Left ventricular mass and body size in normotensive children and adults: assessment of allometric relations and impact of overweight. J Am Coll Cardiol 1992;20:1251-60

[2] Chirinos JA, Segers P, De Buyzere ML, Kronmal RA, Raja MW, De Bacquer D, et al. Left ventricular mass: allometric scaling, normative values, effect of obesity, and prognostic performance. Hypertension 2010;56:91-8.

(c) 2019 Association for Research into Arterial Structure and Physiology. Publishing services by Atlantis Press International B.V. This is an open access article distributed under the CC BY-NC 4.0 license (http://creativecommons.org/licenses/by-nc/4.0/). 